\title{
Letter to the Editor: A response to Zachut (2020)
}

\section{Uzi Moallem* (i)}

Animal Science, Volcani Center, PO Box 6, Bet Dagan 20742, Israel
The suggested insight in Zachut (2020) is reasonable and the hypothesis should be explored thoroughly in future research dealing with n-3 fatty acids supplementation to dairy cows. The hypothesis is based on the assumption that arachidonic acid (C20:4n-6) is a precursor of endocannabinoid synthesis and that reducing the n-6:n-3 ratio in diet will lower the availability of arachidonic acid in tissues, leading to reduced endocannabinoid system activity. Indeed, the findings of our previous reports with dietary supplementation of $n-3$ fatty acids (reducing the n-6:n-3 ratio in diet) demonstrated a decrease in the arachidonic acid proportion in a variety of tissues. The proportion of arachidonic acid in plasma was decreased in cows supplemented with $\alpha$-linolenic acid (ALA; $1.68 \%$ in the controls vs. $1.19 \%$ in ALA cows; Moallem et al., 2013), as well as in plasma of bulls supplemented with ALA $(2.07 \%$ in controls vs. 1.61\% in the ALA bulls; Moallem et al., 2015). A lower proportion of arachidonic acid was found in adipose tissues of cows fed a lower n- 6 :n- 3 ratio $(0.16 \%$ in controls vs. $0.06 \%$ in the n-3-supplemented cows; Zachut et al., 2010). Furthermore, in cows fed a diet with a lower n-6:n-3 ratio, we found a reduction in the proportion of arachidonic acid in follicular fluid of preovulatory follicles $(2.08 \%$ in controls vs. $0.93 \%$ in the $\mathrm{n}-3$ cows $)$ and in granulosa cells $(0.21 \%$ in controls vs. $0.03 \%$ in the $\mathrm{n}-3$ cows; Zachut et al., 2011). Thus, the effects of n-3 fatty acids on the reproductive system might be partly mediated by the reduced availability of arachidonic acid. In summary, our findings support the hypothesis suggested in Zachut (2020) on the involvement of the endocannabinoid system in the mechanism explaining the effects of n-3 fatty acids on physiology and reproduction in dairy cows.

\section{REFERENCES}

Moallem, U., N. Neta, Y. Zeron, M. Zachut, and Z. Roth. 2015. Dietary $\alpha$-linolenic acid from flaxseed oil or eicosapentaenoic and docosahexaenoic acids from fish oil differentially alter fatty acid composition and characteristics of fresh and frozen-thawed bull semen. Theriogenology 83:1110-1120. https://doi.org/10.1016/j .theriogenology.2014.12.008.

Moallem, U., A. Shafran, M. Zachut, I. Dekel, Y. Portnick, and A. Arieli. 2013. Dietary $\alpha$-linolenic acid from flaxseed oil improved folliculogenesis and IVF performance in dairy cows, similar to eicosapentaenoic and docosahexaenoic acids from fish oil. Reproduction 146:603-614. https://doi.org/10.1530/REP-13-0244.

Zachut, M. 2020. Letter to the editor: Are the physiological effects of dietary n-3 fatty acids partly mediated by changes in activity of the endocannabinoid system in dairy cows? J. Dairy Sci. 103:10491049. https://doi.org/10.3168/jds.2019-17328.

Zachut, M., A. Arieli, H. Lehrer, L. Livshitz, S. Yakoby, and U. Moallem. 2010. Effects of increased supplementation of n-3 fatty acids to transition dairy cows on performance and fatty acid profile in plasma, adipose tissue, and milk fat. J. Dairy Sci. 93:5877-5889. https://doi.org/10.3168/jds.2010-3427.

Zachut, M., A. Arieli, and U. Moallem. 2011. Incorporation of dietary n-3 fatty acids into ovarian compartments in dairy cows and the effects on hormonal and behavioral patterns around estrus. Reproduction 141:833-840. https://doi.org/10.1530/REP-10-0518.

\section{ORCIDS}

Uzi Moallem ๑ https://orcid.org/0000-0001-7958-0885

Received October 28, 2019.

Accepted October 30, 2019

*Corresponding author: uzim@volcani.agri.gov.il 